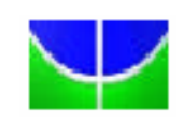

Universidade de Brasília

Centro de Excelência em Turismo

\title{
Manual de Boas Práticas de Fabricação em Indústria de Gelo .
}

\section{Alessandro Pereira Del Rio}

\author{
ORIENTADORA \\ Lucianne Cardoso
}

Monografia apresentada ao Centro de Excelência em Turismo da Universidade de Brasília como requisito parcial para a obtenção do grau de Especialista em Qualidade de Alimentos

Brasília, DF, Abril, 2004 
UNIVERSIDADE DE BRASÍLIA

Centro de Excelência em Turismo

Curso de Especialização em Qualidade de Alimentos

\section{Manual de Boas Práticas de Fabricação}

Em Indústria de Gelo.

\section{Alessandro Pereira Del Rio}

Banca examinadora

Lucianne Cardoso,Mestrado

Orientadora 
"ciência, em lugar de empirismo harmonia, em vez de discórdia; cooperação,não individualismo; rendimento máximo, em lugar de produção reduzida desenvolvimento de cada homem, no sentido de alcançar maior eficácia e prosperidade “ F.W. TAYLOR 


\section{Agradecimentos}

Agradecimentos,

Aos meus pais, e irmãos pela paciência e compreensão.

À professora e orientadora, Lucianne Cardoso, pela ajuda na realização deste trabalho. 


\section{Su má ri o}

I - Introdução

II - Revisão Bibliográfica

II - - Objetivo

III - Justificativa.

IV - Materiais e Método

V - Resultado

VI- Discussão.

VII - Conclusão

VIII - Bibliografia

IX - Anexos 


\section{RESUMO}

Atualmente, as indústrias de alimentos estão preocupadas com a garantia da qualidade dos produtos oferecidos ao consumidor. Neste contexto os programas de segurança alimentar surgem como principal alternativa para produção de alimentos inócuos. No que se refere a industrialização de gelo, as BPF - Boas Práticas de Fabricação constituem uma excelente ferramenta para o beneficiamento de alimentos inócuos, em toda a cadeia produtiva.

As boas práticas de fabricação, uma vez implantadas e citadas em manual, asseguram os padrões de qualidade mínimos, assim como os procedimentos de elaboração dos alimentos e de higiene, que quando necessários, devem ser descritos. As normas descritas em ambos, manual e procedimentos, devem ser conhecidas e praticadas por todos os colaboradores da empresa, em maior ou menor profundidade.

A implantação desta ferramenta na Distribuidora de Gelo Paranoá, situada no bairro de Sobradinho, Brasília DF, fez com que os procedimentos operacionais e a relação entre chefia e funcionários mudasse, no sentido de buscar a qualidade total do produto para os consumidores.

O presente trabalho descreve os procedimentos e normas necessárias para a implantação do Manual de Boas Praticas de Fabricação em industria de gelo , com o objetivo de avaliar a qualidade do gelo, por meio de análise microbiológicas, após a implantação do programa de segurança alimentar BPF- Boas Práticas de Fabricação

Palavras chave : segurança alimentar ,alimentos inócuos, microbiológicas 
Nowadays food industries are concerned with the maintenance of the quality of the products offered to their customs. In this context the nourishment safety programs arise as the main alternative for healthy food. Concerning ice production the GMP (Good Manufacturing Practicalities) comprise an excellent tool for the improvement of innocuous products in the whole production chain.

The GMP, once applied and stated in a manual keep the minimum quality standards as well as hygiene and food manufacturing procedures, which must be described when necessary. The rules described in both the procedures and the manual must be known and practiced by all the collaborators of the company, no matter the function they exert in the product's development.

The application of this tool in the Ice Distributor of Paranoa, located in Sobradinho, Brasilia, DF, was responsible for the change in the relationship between employer and employees. This was done to provide the highest quality of their products to the customers.

This work describes the necessary procedures and rules for the implementation of the manual Good Ice Manufacturing Practicalities, with the objective of evaluating the quality of ice production, by means of micro biological analysis, after the implementation of the safety food program GMP.

Key-words : safety food, innocuous products , micro biological analysis 


\section{INTRODUÇÃO}

A garantia da qualidade sanitária de produtos alimentícios faz parte da preocupação dos profissionais envolvidos com o preparo de alimentos. A excelência em qualidade, na fabricação dos produtos, confere credibilidade a uma empresa, à medida que os esforços estão voltados para garantia da saúde do consumidor.

Neste contexto é importante citar o papel do programa de segurança alimentar BPF - Boas Práticas de Fabricação, como uma ferramenta para obtenção dessa qualidade. Programa que são os procedimentos necessários para garantir a qualidade dos alimentos.

Apesar de bastante difundido, algumas empresas relutam na sua utilização, não levando em conta os benefícios de sua implantação.

Algumas indústrias de gelo não possuem programas ou manuais de segurança alimentar, talvez por considerarem que a matéria prima não oferece grandes riscos à saúde. Porém, de acordo com Singh (1992), a água pode conter diversos microrganismos patogênicos, parasitas, metais pesados, dentre outros fatores passíveis de causar tóxicoinfecções.

Diante dessa realidade o presente trabalho tem como objetivo descrever a implantação de um manual de BPF - Boas Práticas de Fabricação na Distribuidora de Gelo Paranoá, localizada no Distrito Federal no bairro de Sobradinho, analisando ainda e descrevendo, a qualidade do gelo destinado ao consumo humano após a implantação do programa. 


\section{DESENVOLVIMENTO}

\subsection{Controle higiênico -sanitário dos alimentos}

Em 1989 a organização mundial de saúde informou que 60\% das doenças de origem alimentar são tóxicoinfecções alimentares, ou seja, os agentes etiológicos encontram-se entre bactérias, vírus, fungos e parasitas, principalmente devido às práticas inadequadas de manipulação, matérias-primas contaminadas, falta de higiene durante a preparação, além de equipamentos e estruturas operacionais deficientes.

Visando melhorar as condições higiênico-sanitárias, envolvendo a produção de alimentos e adequar a ação da vigilância sanitária, o Ministério da Saúde publicou a portaria número 1428 de 26/11/1993 recomendando que seja elaborado um manual de Boas Práticas de Manipulação de Alimentos, baseado nas publicações técnicas da SBCTA, OMS e CODEX ALIMENTARIUM, definindo melhor as condições técnicas para elaboração do manual de Boas Práticas.

As BPF/M - Boas Práticas de fabricação ou Manipulação de alimentos, uma vez implantadas e citadas em manual, asseguram os padrões de qualidade mínimos, assim como os procedimentos de elaboração dos alimentos e de higiene, que quando necessários, devem ser descritos. As normas descritas em ambos, manual e procedimentos, devem ser conhecidas e praticadas por todos os colaboradores da empresa, em maior ou menor profundidade, análises microbiológicas rotineiras para assegurar a qualidade do produto.

No que se refere à industrialização do gelo, a água é considerada um fator determinante para obtenção de um produto de qualidade. Do ponto de vista sanitário, o que realmente põe em risco a saúde pública é a ocorrência de poluição fecal, pela possibilidade de estarem presentes microrganismos patógenos intestinais como bactérias, vírus, protozoários e ovos de helmintos, agentes frequentementes responsáveis por doenças de veiculação hídrica (GELDREICH, 1974). É claro que isto somente é verdadeiro se forem excluídos deste grupo de enfermidades, os envenenamentos ocasionados por substâncias químicas que normalmente são oriundas de despejos industriais (ROCHA, 1974).

No entanto a evidência direta dos agentes patógenos na água é, tecnicamente, bastante difícil. Por estes motivos empregam-se métodos indiretos na investigação da presença ou não de poluição de origem fecal nas águas, pesquisando-se bactérias indicadoras de poluição fecal. Para isto são pesquisadas rotineiramente as bactérias do 
grupo coliforme, pois na maioria das vezes elas estão presentes quando ocorrem este tipo de poluição e ausentes quando não ocorrem tal poluição (CRISTOVÃO et al., 1974; GELDREICH, 1974; BRANCO, 1972; NYSDH, 1971). Deste modo verificando-se a presença de bactéria coliforme em água, pode-se considerar que ela recebeu matéria fecal passando a ser considerada perigosa à saúde humana, pelo fato de ser capaz de veicular microrganismos patógenos intestinais (CETESB, 1993; CRISTOVÃO et al., 1974; BRANCO, 1974; AMERICAN WATER WORKS ASSOCIATION, 1970).

Diante dessa situação, evidencia-se a importância do desenvolvimento de programas de segurança alimentar, como as BPF, para toda e qualquer empresa de industrialização de gelo. As Boas práticas estão baseadas em normas estabelecidas pela legislação vigente pela Portaria 326/97 SUS/MS e pela sua execução RDC Nº 275/02 ANVISA/ POP.

Com isso, as Boas Práticas no sentido de assegurar a qualidade higiênico-sanitário dos alimentos, devem constituir-se em procedimentos que permitam atingir os critérios de segurança de modo amplo. Critérios esses, que serão citados no texto e descritos no manual.

\subsection{O Manual de Boas Práticas de Fabricação}

Boas Práticas são normas de procedimentos para atingir um determinado padrão de identidade e qualidade de um produto ou um serviço na área de alimentos, cuja eficácia e efetividade deve ser avaliada através de inspeção e investigação (SILVA JUNIOR, 2001).

Esse manual de Boas Práticas de Manipulação descreve as condutas em relação a: Funcionários, matérias-primas, controle de pragas, água de abastecimento, visitantes, e condições estruturais, bem como os procedimentos e critérios acerca da higiene, manipulação e transporte dos produtos (SILVA JUNIOR, 2001).

De maneira sistemática, faz o detalhamento das condutas em relação a:

- Funcionários: Controle de saúde por meio de exames médicos, laboratoriais, admissionais, revisionais, demissionais, retorno ao trabalho, e também, de mudança de função. Além de programa de treinamento e monitoramento.

- Matéria-prima: plano de controle microbiológico da água, higiene periódica da caixa de água. 
- Controle de pragas: Proteção contra insetos e roedores, bem como conhecimento das técnicas utilizadas pela empresa desinsetizadoras.

- Água de abastecimento: Higiene e controle dos bebedouros/caixa d água.

- Relatório de avaliação estrutural: Sugestões para adequação das falhas estruturais no que diz respeito a instalações elétricas e instalações hidráulicas.

E dos procedimentos e critérios, em relação à:

- Recebimento de matéria-prima.

- Envase.

- Armazenamento em câmara fria.

- Espera para distribuição.

- Distribuição.

- Alimento transportado.

Condutas para prevenção de tóxico-infecções de origem alimentar:

- Atuando no funcionário.

- Exames laboratoriais: Coprocultura - VDRL, hemograma e caproparasitológico.

- Treinamento: Regras de trabalho geral, regras de higienização, regras de prevenção da contaminação e medidas disciplinares.

- Atuando no ambiente de trabalho.

- Nos equipamentos e utensílios: Higienização adequada, armazenamento correto, fiscalização diária, fiscalização completa e uso adequado.

- Atuando no ambiente de trabalho.

- Higienização adequada, controle integrado de pragas, fiscalização diária e completa e fluxo planejado de atividades.

- Atuando no alimento.

- Análise microbiológica de triagem, análise microbiológica de controle, armazenamento e refrigeração, distribuição.

O Código de Regulamentação Federal do FDA nos Estados Unidos fornece uma relação de Boas Práticas de Fabricação (GMP), dividida em quatro sub-partes. A primeira define os termos relevantes - inclusive "pontos críticos de controle" — e trata de práticas, referente a pessoal. A segunda divisão das GMP trata das instalações. Nesta divisão estão incluídos os requisitos para manutenção das áreas externas; construção de plantas físicas; 
ventilação e iluminação adequadas; controle de pragas; uso e armazenamento de produtos químicos (incluindo substâncias sanitizantes); abastecimento de água e encanamentos; e coleta de lixo. A terceira parte aborda os requisitos gerais para equipamento, incluindo aqueles necessários para construção, facilidade de limpeza e manutenção. A última parte aborda controles de produção. Essa sub parte é a mais detalhada das quatro e, ao contrário das três primeiras que especificam de um modo geral, determina que o processo deve ser controlado de maneira sanitária, tomando as precauções e usando os controles adequados para prevenir a contaminação, a regulamentação desta sub parte trata de cada etapa da produção (FERRREIRA 2003)

\subsection{Procedimento Padrão de Higiene Operacional ( SSOP )}

O cumprimento das Boas Práticas de Fabricação e das exigências sanitárias é a base para a produção de alimentos inócuos. Os Procedimentos Padrão de Higiene Operacional são programas considerados parte das GMP. Há duas classificações para os SSOP, conforme sua origem, ou seja, se a partir do FDA (Food and Drug Administration) ou do FSIS (Food Safety Inspection Service, USA). ( FDA 1997)

De acordo com as Boas Práticas de Fabricação Atuais, Embalagem ou Conservação de Alimentos para o Consumo Humano do FDA, os SSOP devem abordar os seguintes aspectos:

- Manutenção geral: edifícios, instalações e outros locais da planta devem ser mantidos em condições higiênicas e em bom estado. A limpeza e a sanitização de utensílios e equipamentos devem ser realizadas de modo a evitar contaminação dos alimentos, das superfícies em contato com os mesmos e do material de embalagem.

- Substâncias usadas na limpeza e sanitização; armazenamento de materiais tóxicos: os produtos usados nos procedimentos de limpeza e sanitização não devem conter microrganismos indesejáveis e devem ser inócuos e adequados conforme as condições de uso.

- Controle de pragas: Nenhuma praga deve estar presente nas áreas de processamento de alimentos. Devem-se tomar medidas eficazes para eliminá-las e para proteger os alimentos contra a contaminação. O uso de inseticidas ou raticidas é permitido somente com precauções e restrições que protejam os alimentos, as superfícies em contato com alimentos e os materiais de embalagem contra contaminação. 
- Higiene das superfícies, em contato com alimentos: Todas as superfícies em contato com alimentos, incluindo utensílios e as superfícies de equipamentos devem ser limpas com a freqüência necessária para proteger os alimentos contra a contaminação.

As superfícies, em contato com alimentos, usadas para manipulação ou conservação com pouca umidade devem estar secas e em condições higiênicas no momento do uso. Após a limpeza de superfícies, deve-se, quando necessário, higienizá-las e secá-las completamente antes de novo uso.

No processamento úmido a limpeza é necessária para proteger os alimentos de modo a não entrarem em contato com os microrganismos, e todas as superfícies em contato com alimentos devem ser limpas e higienizadas antes do uso e depois de cada interrupção, quando elas podem se contaminar. Nos casos de operação contínua de produção, os utensílios e as superfícies dos equipamentos que entram em contato com os alimentos devem ser limpas e higienizadas quando necessário.

As superfícies de equipamentos que não entram em contato com alimentos e que são usadas em operações de plantas de alimentos devem ser limpas sempre que for necessário para proteger os alimentos contra contaminação.

Artigos descartáveis (como copos plásticos e toalhas de papel) devem ser armazenados em recipientes apropriados e manipulados, distribuídos, usados e descartados de modo que os alimentos e as superfícies em contato com alimentos não sejam contaminados.

Os agentes sanitizantes devem ser apropriados e seguros para as condições de uso. Qualquer instalação, procedimento ou máquina é aceito para limpeza e sanitização de equipamentos e utensílios, desde que permitam a sanitização adequada do equipamento e utensílios e que os mesmos possam ser limpos adequadamente.

- Armazenamento e manipulação de equipamento e utensílios portáteis limpos: Os equipamentos portáteis com superfícies em contato com alimentos e utensílios, já limpos e higienizados, devem ser armazenados em local apropriado, de modo a proteger estas superfícies contra a contaminação.

Cada planta deve estar equipada com instalações sanitárias adequadas e serventias que incluem, mas não se limitam apenas a: 
- Abastecimento de água. O abastecimento de água deve ser suficiente para as operações pretendidas e deve ser de uma fonte adequada. Toda água que entra em contato com os alimentos ou com as superfícies em contato com alimentos deve ser inócua e de qualidade sanitária adequada.

- Encanamentos. Os encanamentos devem ser de tamanho e desenho adequados, e instalados e conservados de modo a :

1) conduzirem quantidade suficiente de água para as áreas da planta solicitadas.

2) transportar de forma apropriada as água residual e os resíduos líquidos da planta.

3) evitar que se torne uma fonte de contaminação para alimentos, abastecimento de água, e para equipamentos ou utensílios.

4) fornecer drenagem adequada de piso em todas as áreas sujeitas à limpeza úmida ou onde as operações normais deságüem ou liberem líquido residual no piso.

5) não causar refluxo ou conexão cruzada entre os sistemas de encanamento que levam água residual ou esgoto e aqueles que transportam água para os alimentos ou para sua fabricação.

- Escoamento de esgoto. A disposição de esgoto deve ser realizada em um sistema de esgotos adequado ou através outro meio apropriado.

- Banheiros. Cada planta deve fornecer aos seus funcionários banheiros adequados e de fácil acesso, sem comunicação direta com a área de manipulação de alimentos.

- Instalações para lavagem de mãos. Os lavatórios devem ser adequados e cômodos, abastecidos com água corrente em temperatura agradável. Cumpre-se essa exigência oferecendo:

1) instalações para lavar e, quando necessário, higienizar, as mãos em cada ponto da planta onde as boas práticas de higiene exijam que os funcionários lavem e/ou higienizem as mãos.

2) produtos eficientes para lavar e higienizar as mãos.

3) toalhas higiênicas (papel branco) ou instalações adequadas para secagem das mãos.

4) dispositivos ou instalações, como válvulas de controle de água, projetadas e construídas para proteger as mãos limpas e higienizadas contra a recontaminação; 
5) sinais de compreensão imediata, que orientem os funcionários que manipulam alimentos, materiais de embalagem ou superfícies em contato com alimentos sem proteção, para lavar e, quando apropriado, higienizar as mãos antes do início do trabalho, depois de cada ausência do posto de trabalho, e quando as mãos estejam sujas ou contaminadas.

6) lixeiras construídas e mantidas de modo a proteger contra contaminação de alimentos.

- Retirada de lixo e resíduos: Lixo e resíduos devem ser transportados, armazenados e descartados para minimizar a formação de odor, minimizar o potencial do lixo se tornar um atrativo e albergue, ou lugar de reprodução para pragas, e proteger contra a contaminação de alimentos, superfícies em contato com alimentos, abastecimento de água e pisos.( FSIS,1997).

De acordo com o FSIS (1997), todo estabelecimento que lida com alimentos deve elaborar, manter e cumprir as determinações, por escrito, do plano SSOP. Os SSOP abordam todas os procedimentos diários de higiene operacional e pré-operacional que o estabelecimento deve implementar para evitar contaminação direta e adulteração dos produtos.

O primeiro requisito é que o estabelecimento tenha um plano por escrito, descrevendo todos os procedimentos que realizará antes e durante as operações, e a freqüência dos procedimentos para evitar contaminação direta ou adulteração de produtos. O objetivo é evitar contaminação direta do produto e ter procedimentos para ação imediata nos casos em que ocorre a contaminação direta do produto.

O segundo requisito é o plano ser assinado e datado por um funcionário responsável pelo setor ou mais graduado no estabelecimento. O plano deve ser assinado quando implantado e sempre que modificado.

O terceiro requisito é o plano SSOP identificar os procedimentos sanitários préoperacionais e distingui-los das atividades de sanitização realizadas durante as operações. Estes procedimentos pré-operacionais devem abordar, pelo menos, a limpeza de superfícies em contato com alimentos, equipamentos e utensílios. Esta exigência deve levar as indústrias a colocarem questões como, por exemplo, quão específicos devem ser os 
procedimentos. As plantas podem, mas não são obrigadas a fornecer detalhes no plano SSOP, por escrito, sobre limpeza e monitoramento de cada equipamento específico.

O quarto requisito é o plano SSOP, por escrito, identificar as pessoas responsáveis pela implementação e manutenção das atividades diárias de saneamento. As plantas devem identificar essa(s) pessoa(s) pelo nome ou pelo cargo. Não há nenhuma exigência de que essas pessoas ou cargos tenham autoridade diferente daquela do processo de produção. Pode-se identificar funcionários de produção, chefes de setor ou de departamento, etc., para atender a essa exigência.

O quinto, e último, requisito do FSIS é o estabelecimento manter registros diários para demonstrar que os procedimentos sanitários descritos no plano SSOP são executados, incluindo as ações corretivas tomadas. Não há exigência de se usar um formato estabelecido, apenas que os registros sejam mantidos. Os registros podem ser mantidos em computador, em vez de cópias por escrito, desde que estejam disponíveis ao pessoal de fiscalização.

\subsection{PCC’s (Pontos Críticos de Controle)}

Qualquer ponto, etapa ou procedimento no qual se aplicam medidas de controle preventivas para manter um perigo significativo sobre controle, com o objetivo de eliminar, prevenir, ou reduzir os riscos à saúde do consumidor (DIAS, 2003).

Esses pontos são estabelecidos para o desenvolvimento das BPF, no sentido de garantir a produção inócua dos produtos.

Para determinação dos PCC's desenvolve-se primariamente um fluxograma de operações de produção, com posterior desenvolvimento de um questionário chamado ‘'Arvore Decisória de PCC’s’, que identifica os tipos de perigos e suas relevâncias.

\subsubsection{Características de matéria-prima}

A água potável utilizada como matéria-prima deve atender aos parâmetros de qualidade estabelecidos nas diretrizes mais recentes da Organização Mundial da Saúde (OMS) apresentar as seguintes propriedades organolépticas:

Características físico-quimicas.

- Cor aparente: Até 5,0 uH.

- Odor: Não abjetável.

- Sabor: Não objetável 
- Turbidez: até 1,0 uT.

$-\mathrm{pH}: 6,5$ a 8,5 .

- Teor de cloro ativo : Mínimo de 0,2 mg/L.

- Características Microbiológicas:

- Ausência de bactérias do grupo Coliformes Fecais em 100 ml de amostras.

- Ausência de bactérias do grupo Coliformes Totais em 100 ml de amostras.

- Tolerância de até 500 UFC/ml para bactérias Heterotróficas.

- Características Macroscópicas:

- Ausência de sujidades, larvas e parasitos.

\subsection{Os fatores significativos que contribuem para a contaminação do gelo}

Os fatores significativos que contribuem para a contaminação dos alimentos são:

- Matéria-prima contaminada: O gelo elaborado com água contaminada, pode transmitir doenças bacterianas causadas por Shigella, Salmonella, Escherichia coli enteropatogênica, Caampylobacterjejuni e vibreo cholerae ( SINGH E MEFETERS, 1992 )

- Pessoas infectadas que manipulam o produto.

- Contaminações cruzadas.

- Limpeza e desinfecção inadequadas de equipamentos e utensílios de preparação.

- Adição substâncias inadequadas ou fora de conformidade (ex: cloro em excesso) em caixa d’água.

- Presença de substâncias venenosas.

- Contaminação durante envase.

- Contaminação durante estocagem.

- Contaminação durante transporte.

\subsection{Método de análise de matéria-prima}

As amostras de gelo para estudo são coletadas após o processamento. Para se coletar tais amostras são utilizados frascos esterilizados para acondicionamento, que serão estocados em câmara fria com temperatura inferior a $-10^{\circ} \mathrm{C}$, ou em caixas térmicas para transporte até o local de análise. Utiliza-se luvas para o manuseio das amostras, álcool a 92,8\% para limpeza do reservatório de amostras. 
As análises microbiológicas irão determinar a presença ou ausência de coliformes totais em 100ml de amostra, coliformes termo-tolerantes em 100ml de amostra, e Escherichia coli em 100ml de amostra. 


\section{Objetivo}

Avaliar a qualidade do gelo, por meio de análise microbiológicas, após a implantação do programa de segurança alimentar BPF- Boas Práticas de Fabricação.

\section{Justificativa}

Atualmente, as indústrias de alimentos estão preocupadas com a garantia da qualidade dos produtos oferecidos ao consumidor. Neste contexto os programas de segurança alimentar surgem como principal alternativa para produção de alimentos inócuos. No que refere a industrialização de gelo, as BPF - Boas Práticas de Fabricação constituem uma excelente ferramenta para o beneficiamento de alimentos inócuos, em toda a cadeia produtiva. 


\section{Material e Método}

Foram utilizadas bibliografias nacionais e internacionais como base teórica para a confecção e implantação de Manual de Boas Práticas de Fabricação em uma indústria de gelo.

A análise laboratorial foi realizada pelo Laboratório Central de Saúde Pública-

LACEM, visando garantir a qualidade do produto após a implantação das BPF ( Boas Práticas de Fabricação ). 
6. Resultado

\section{MANUAL DE BOAS PRÁTICAS DE FABRICAÇÃO}

\section{INTRODUÇÃO}

Esse manual tem com principal objetivo, assegurar que todos os envolvidos no processo de produção de gelo tenha o conhecimento das Normas de Higiene e Qualidade, que são adotadas pela empresa, para que nosso produto chegue ao conhecimento final, livre de qualquer impureza e dentro do mais rigoroso padrão de qualidade.

\section{0) PORTARIA DO MS N³6 DE 19/01/1990}

\section{1) DEFINIÇÃO}

Gelo o produto produzido a partir da solidificação de água potável ( aquela com qualidade adequada ao consumo humano).

\section{2) DESIGNAÇÃO}

O produto é designado por gelo em cubos.

\section{3) CARACTERISTICAS GERAIS}

O produto deve ser preparado com água potável de boa qualidade, dentro do conjunto de valores máximo permissíveis, das características da água destinado ao consumo humano. No caso de nossa empresa é utilizada a água do serviço de abastecimento público (CAESB).

\section{4) CARACTERISTICAS FISICO-QUIMICA}


Cor aparente : Até 5,0 uH

Odor: Não objetável

Sabor : Não objetável

Turbidez: até 1,0 uT

pH: 6.5 a8.5

Teor de Cloro ativo: Mínimo de $0.2 \mathrm{mg} / \mathrm{L}$

\section{5) CARCATERÍSTICAS MICROBIOLOGICAS}

Ausência de bactérias de grupos coliformes fecais em 100ml de amostras.

Ausência de bactérias de grupos coliformes totais em 100ml de amostras.

Tolerância de ate 500 UFC/ml para bactérias heterotróficas.

Deveram ser efetuadas determinação de microrganismos, sempre que se tomar necessário a obtenção de dados adicionais sobre o estado higiênico- sanitário do produto.

\section{6) CARACTERISCAS MACROSCÓPICAS}

Ausência de sujidades, larvas e parasitos.

\section{0) CONDIÇOES AMBIENTAIS}

\section{1) ÁREA DE TRABALHO}

Existem espaços suficientes e adequados para os equipamentos de produção, de estocagem(câmara frigorifica), material auxiliares de forma e garantir o livre acesso a todas as dependências e maquinas, e ainda permite a manutenção e limpeza de todas as áreas e equipamentos

\section{2) CONTAMINAÇÃO}

A contaminação cruzada é evitada por barreiras físicas entre a recepção, depósito, sanitários, área de produção e estocagem. 


\section{3) TRANSPORTE}

O transporte do produto final é efetuado por pessoa devidamente uniformizada, em automóvel próprio, tipo FIAT/Fiorino/Furgão fechado devidamente higienizado e caminhão térmico equipado com termômetro para o controle da temperatura.

\section{4) PAREDES E TETOS}

As paredes e teto da área de produção são pintados com tinta de cor branca, impermeável de modo a proporcionar uma fácil visualização de quaisquer sujeiras e sua conseqüente limpeza.

\section{5) PISO}

O piso é cerâmico (área de produção) e de cimento liso, que é higienizado diariamente, com produtos químicos adequados.

\section{6) RALOS}

Dispostos de maneira a evitar o acúmulo de água na área de produção e sanitários. São limpos periodicamente.

\section{7) ILUMINAÇÃO}

É feita com lâmpadas incandescentes, na potência adequada.

\section{8) LAVATÓRIO}

Existe um lavatório no banheiro, com detergente desinfetante para as mãos, com saboneteira e toalhas de papel descartáveis. 


\section{0) INSTALAÇÕES E SANEAMENTO}

\section{1) INSTALAÇÕES ELÉTRICAS}

O circuito de alimentação dos equipamentos de produção é independente, tripolar e com fios na bitola adequada e em cores diferentes para facilitar a identificação, dentro das normas da ABNT, respeitando as potências dos equipamentos neles conectados.

\section{2) INSTALAÇÕES HIDRÁULICAS}

Existem pontos de água nos locais necessários, um ponto na área de produção, um ponto na área de envase e outro na casa de máquinas.

\section{3) SANEAMENTO}

\subsection{1) ÁGUA}

Proveniente do reservatório da concessionária (CAESB), onde já recebe tratamento adequado. A caixa d’água é limpa e higienizada com a periodicidade trimestral.

\subsection{2) ESGOTO}

Todas as instalações são adequadas, obedecendo às normas da concessionária. As caixas de esgoto possuem tampas e são limpas semestralmente ou conforme necessidade pela própria empresa seguindo recomendações oficiais.

\subsection{3) LIXO}

O lixo é embalado em sacos plásticos e o mesmo recolhido diariamente, ou quando se fizer necessário. 


\subsection{4) PROTEÇÃO CONTRA INSETOS E ROEDORES}

- Ralos com fechamento manual e sanitizados diariamente.

- Avisos nos locais adequados, solicitando a observância das normas de higiene.

- Máquinas localizadas em posição a facilitar a limpeza (afastadas da parede).

- Lixeiras com tampas

\section{0) EQUIPAMENTOS E UTENSÍLIOS}

\section{1) SELADORA}

Destinada a fechar embalagens, para garantir a qualidade do produto final produzido.

\subsection{1) LIMPEZA}

Realizada diariamente utilizando-se uma esponja com água e detergente e depois sanitizando com álcool a 70\%.

\section{2) BALANÇA}

Utilizada para aferir a dosagem nas embalagens.

\subsection{1) LIMPEZA}

Realizada diariamente utilizando-se uma esponja com água e detergente e depois sanitizando com álcool a 70\%.

\section{3) CAMARA FRIGORÍFICA}

Utilizada para o armazenamento e manutenção do produto final, devidamente embalado. 


\subsection{1) LIMPEZA}

Será efetuada com periodicidade mensal, ou quando se fizer necessário. Percebendo a presença de odores estranhos ou gelo em excesso, deve-se proceder o degelo do equipamento. Para isso retirar todos os produtos, tendo o cuidado de acondicioná-los em local apropriado, desligar a câmara e manter a porta aberta. Tirar a tampa do dreno e posicionar um vasilhame para recolher a água. Não utilizar nenhum produto químico, detergentes fortes ou esponjas grossas para fazer a limpeza. Lavar as paredes internas e externas com água morna e sabão neutro. Secar bem as paredes, recolocar os produtos e ligar a câmara.

\section{0) RECURSOS HUMANOS}

Todas as pessoas que tenham contato com o processo, matéria-prima, material de embalagem, produto final, equipamentos e utensílios, devem estar treinadas e conscientizadas a praticar medidas de higiene e segurança do produto, a seguir descritas, para proteger o produto de contaminações químicas e microbiológicas.

\section{1) PROCESSO DE SELEÇAO}

\subsection{1) EXAME MÉDICO ( PCMSO)}

O candidato a vaga na empresa, só poderá ser admitido após apresentação de atestado medico que comprove boas condições de saúde.

\subsection{2) EXAME DE CAPACITAÇAO}

Será dada a preferência a pessoas que já possuam experiência na área alimentícia ou de processamento de alimentos.

\section{2) PROCESSO DE TREINAMENTO}

Toda a pessoa admitida deverá , antes de iniciar suas atividades na empresa, tomar conhecimento de todas as normas, através de leitura do Manual de Boas Praticas de 
Fabricação. Quaisquer dúvidas que venham a surgir, sobre o processo de produção ou regras de higiene, devem ser esclarecidas por profissionais do setor

\section{3) CONTROLE DE SAÚDE}

- O exame médico é renovado periodicamente ou após afastamento por enfermidade.

- Nenhuma pessoa que esteja afetada por enfermidade infecto-contagiosa ou que apresente inflamações, infecções, ou afecções na pele, feridas ou outras anormalidades que possa originar contaminação microbiológica do produto, do ambiente ou de outros individos, é admitida para trabalhar no processo de manipulação do produto.

- As pessoas com curativos não manipulam o produto.

- A pessoa que apresentar qualquer das situações descritas acima, é direcionadas a outro tipo de trabalho que não seja a manipulação do produto.

\section{4) HÁBITOS DE HIGIENE}

Todos os empregados devem evitar a pratica de atos não sanitários, tais como: coçar a cabeça, introduzir dedos nas orelhas, nariz e boca. Evitam tocar com as mãos no produto final. Antes da embalagem, exceto no caso de necessidades operativas e desde que as mãos estejam adequadamente lavadas e desinfectadas,

- Antes de tossir ou espirrar, afastar-se do produto que esteja manipulando, cobrir a boca e o nariz com lenço de papel ou tecido adequado e depois lavar e desenfectar as mãos para prevenir contaminações,

- Os homens devem estar sempre bem barbeados, para ajudar a promover um ambiente de limpeza. Barba longa deve ser evitada e, em casos específicos, até proibida, para o pessoal da área de produção,

- Os cabelos dos homens devem ser mantidos bem aparados. Homens e mulheres devem cabelos totalmente cobertos através do uso de tocas, redes ou similares,

- As unhas devem ser mantidas curtas, limpas e livres de qualquer tipo de esmalte, 
- As mãos apresentam-se sempre limpas. Devem ser lavadas com água e sabão e desinfetadas antes do inicio do trabalho e depois de cada ausência do mesmo (o uso de sanitários ou outras ocasiões em que as mãos tenham se sujado ou contaminado).

\section{5) VESTUÁRIO}

- Usar uniforme ou roupa externa ( avental ) de cor clara sobre o vestuário, antes de se iniciar as atividades na área de produção,

- O uniforme é mantido em bom estado, sem rasgos, partes descosturadas ou furos, conservado limpo durante o trabalho e trocado diariamente,

- Quando o trabalho em execução propiciar que os uniformes se sujem rapidamente, usase avental plástico para aumentar a proteção contra contaminação do produto,

- Os calçados devem sempre se apresentar limpos e em boas condições. É evitado calçados de lona,

- No caso de uso de luvas para manuseio do produto, material de limpeza,etc., estas são mantidas de forma perfeita e limpa. Devem, também, ser de material impermeável e adequada ao tipo de trabalho a ser realizar. O uso de luvas não elimina a necessidade de lavar as mãos.

\section{6) CUIDADOS ESPECIAIS}

- Para evitar a possibilidade de certos objetos caírem no produto, não é permitido carregar no uniforme, canetas, lápis, termômetros, espelhinhos, etc., especialmente da cintura para cima,

- Roupas e pertences pessoais, não devem ser guardados em locais onde estejam expostos o produto final ou em áreas usadas para limpeza de equipamentos ou utensílios ou sobre equipamentos utilizados no processo,

- A entrada de alimentos ou bebidas na área de produção não deve ser permitida, exceto nas áreas reservadas para esse fim, 
- Almoço e lanche, enquanto não consumidos, devem ser guardados nos lugares designados para tal fim, além da obrigatoriedade de estarem bem acondicionados,

- A guarda de alimentos nos armários (roupeiros) e gavetas dos empregados não é permitida,

- Não é permitido fumar na área de produção

- Mascar chicletes ou manter a boca palitos de dentes, fósforos, doces ou similares durante a permanência na área de trabalho, não é permitido. Tão pouco manter lápis, cigarros ou outros objetos atras da orelha,

- Anéis, brincos, pulseiras, colares, relógios, amuletos e outros adornos não são permitidos durante o trabalho, devido ao fato de que:

- Os adornos das mãos não podem ser adequadamente desinfetados, já que os Microorganismos podem se alojar dentro ou sob as mesmas;

- Existe perigo de que as partes dos adornos se soltem e caiam sob o produto;

- Os adornos pessoais apresentam riscos para segurança pessoal e integridade dos produtos e equipamentos;

- Os empregados da área de administrativa e os visitantes deverão ajustar-se as Normas de Boas Praticas de Fabricação.

\section{0) TECNOLOGIA EMPREGADA}

Para obtenção do produto final, utiliza-se água potável da concessionária ( CAESB ), que passa por 2 (dois ) filtros, o primeiro com 6 (seis) estágios, contendo carvão ativado e o segundo de prata coloidal ( poder germicida ). A água, a ser transformada em gelo, passa primeiro pelo filtro e logo após e armazenada em um reservatório ( caixa d'àgua ) e depois vai para o segundo filtro ( prata coloidal ), onde é lançada para a máquina encarregada de transformá-la em gelo.

\section{1) EMBALAGEM}

As embalagens recebem, em local apropriado no seu rótulo, a data de fabricação e o prazo de validade e são dispostas para controle. Após receberem os cubos de gelo é efetuada a conferência do peso, as mesmas são seladas em equipamentos apropriados. 


\section{2) CONGELAMENTO E ESTOCAGEM}

O congelamento e armazenamento é realizado em câmara frigorifica com temperatura inferior $\mathrm{a}-10^{\circ} \mathrm{C}$.

\section{3) DISTRIBUIÇAO}

O produto é transportado em veículo isotérmico com controle de temperatura.

\section{0) CONTROLE DE QUALIDADE}

É realizado pelo proprietário ( Gerente de Produção ), que inspeciona pessoalmente cada fase da produção.

\section{0) GARANTIA DE QUALIDADE}

Com objetivo de garantir e manter a qualidade do nosso produto nunca diminua, os seguintes critérios de manutenção e avaliação são tomados:

- O Manual de Boas Práticas de Fabricação fica em local visível e de fácil acesso para todos os funcionários envolvidos, direta e indiretamente no processo de produção, para que utilizem os princípios corretos de produção e o controle de qualidade seja mantido em todas as etapas,

- São efetuadas, com periodicidade mensal, análises microbiológicas e físicoquímicas em todas as etapas da produção, para garantir a qualidade do produto em todas as etapas. Os laudos ficarão em poder do Gerente de Produção, que em caso de anormalidade tomará as devidas providencias,

- Há uma pasta com resultados de relatórios e vistorias (assessoria técnica). 


\section{0) ARMAZENAMENTO}

O produto final é armazenado em câmara frigorífera com temperatura inferior a $-10^{\circ} \mathrm{C}$.

\section{0) TRANSPORTE}

O produto é transportado em veículo isotérmico com controle de temperatura.

\section{1) INFORMAÇÕES AO CONSUMIDOR}

$\mathrm{O}$ produto deve ser conservado sob congelamento $\left(-10^{\circ} \mathrm{C}\right)$ em sua embalagem original.

\section{1) PRAZO DE VALIDADE}

Se forem obedecidas as normas de conservação, o prazo de validade do produto é de 06 (seis) meses.

\section{2) PESO}

O produto é comercializado em embalagens de 03 (três) e 05 (cinco) quilos.

\section{2) EMBALAGEM E ROTULAGEM}

A embalagem empregada no produto deve ser obedecer aos seguintes requisitos:

- Proteger as características organolépticas de qualidade do produto

- Proteger o produto contra a contaminação microbiológica e qualquer outro tipo, inclusive a causada pelo próprio material da embalagem.

- Impedir a perda do produto em estado líquido, contra qualquer vazamento.

\section{1) ROTULAGEM}

Contém no rótulo do produto:

- A expressão GELO EM CUBOS, AGUA FILTRADA.

- Instruções para conservação, inclusive a temperatura.

- Instruções de uso. 
- Prazo de validade, data de fabricação e peso do produto.

- Dados completos da empresa.

- Número do registro no ministério da saúde/SUS/DF.

- Telefone para o consumidor.

\section{3) EXPOSIÇÃO E COMERCIALIZAÇÃO}

Para expor e comercializar o produto, os estabelecimentos são orientados, pelo vendedor da empresa, sobre os procedimentos que devem ser seguidos para manter a qualidade do mesmo, sendo;

- O produto deve ficar acondicionado em freezers

- Mantido na temperatura adequada

- Observar sempre o prazo de validade

- Embalagens abertas, danificadas ou violadas não podem ser comercializadas.

- Comercializar sempre o lote mais antigo, para isso deve-se utilizar o rodízio da mercadoria.

\section{4) DESINFECÇÃO/DESINFESTAÇÃO}

A desinfecção é realizada diariamente, por produtos químicos adequados (desinfetantes clorados, etc).

A desinfestação é efetuada com periodicidade trimestral, ou quando se perceber a necessidade, através da contratação de empresa especializada. Ainda assim, são tomadas por todos os funcionários, com supervisão direta do Gerente de Produção, medidas que visam prevenir a proliferação de insetos e roedores, sendo;

- Evitar água empoçada ou estagnada

- Retirada diária do lixo

- Armários e equipamentos encostados nas paredes

- Limpeza geral no início e término do expediente

- Ralos abertos

De qualquer forma, verifica-se que o nosso ambiente não é propício à manifestação de insetos e roedores. 


\section{6) DISCUSSÃO}

O manual de Boas Praticas de Fabricação é uma das ferramentas mais importantes para obtenção da qualidade de produtos alimentícios, e no caso, do gelo.

A implantação desta ferramenta na Distribuidora de Gelo Paranoá, situada no bairro de Sobradinho, em Brasília DF, fez com que os procedimentos operacionais e a relação entre chefia e funcionários mudasse, no sentido de buscar a qualidade total do produto para os consumidores.

A empresa possuía vários pontos que estavam em desacordo com o manual de Boas Praticas de Fabricação como transporte, armazenamento e envase.

O meio de transporte não era adequado para sua função, pois não apresentava isolamento térmico, nem termômetros para controle da temperatura.

O aumento de temperatura no decorrer do transporte era um grande problema, pois poderia possibilitar a formação de água no fundo da embalagem, descaracterizando o produto após novo congelamento nos pontos de revenda, além de favorecer o desenvolvimento de microorganismos patogênicos tornando o produto inviável para o consumo humano.

Esse problema foi superado, com o investimento em veículos fechado, isotérmicos e refrigerados, constituídos de material liso, resistente, impermeável e atóxico, além de termômetros para o controle da temperatura no decorrer do transporte.

Com relação ao armazenamento, se não for correto, o gelo pode sofrer alterações decorrente a ação de microrganismos. Estas alterações se tornam evidentes em relação às características microbiológicas, sensoriais, físico-químicas e nutricionais.

Por se tratar de um produto congelado, o gelo após envase deve ser estocado, ou seja, armazenado em câmara fria ou freezer com temperatura que pode variar de $-18^{\circ} \mathrm{C}$ à $10^{\circ} \mathrm{C}$.

A câmara de estocagem deve possuir termômetro regulado para garantir a qualidade do produto. Sempre que necessário o termômetro deve ser ajustado segundo o manual de boas praticas da empresa

A entrada do produto na câmara de armazenamento deve ser feita pela porta de entrada de mercadoria para garantir a qualidade do produto evitando assim o risco de 
contaminação cruzada, o que não era realizado antes da implantação do manual de boas praticas de fabricação.

O gelo estocado na câmara fria deve ser empilhado sobre palete para evitar o contato do saco de gelo com o chão, facilitando assim o ciclo do produto no interior da câmara e garantido a saída do lote mais antigo para a venda

No momento do envase a empresa também possuía problemas pois os funcionários não possuíam treinamento especifico para o empacotamento do produto.

A solução que a empresa teve para superar esse ponto critico foi o treinamento dos funcionários, realizado mensalmente ou quando necessário. 


\section{7- Conclusão}

As Boas Práticas de Fabricação são ferramentas de segurança alimentar que quando implantadas de maneira efetiva garantem a produção de produtos inócuos, diminuindo o risco de ocorrência de problemas de saúde pública.

Os cuidados com a produção de gelo deve ser diário , constantes e atribuídos a toda cadeia de produção. Estes cuidados abrangem desde a matéria-prima, utilização de utensílios higienizado, envase, estocagem em temperatura adequada , transporte em veículos isotérmicos até chegarem ao consumidor final.

O monitoramento periódico, feito através de análises microbiológicas e fisicoquímicas, apesar do alto custo, são importantes pois fornecem subsídios técnicos para uma melhor visão de como esta sendo desenvolvendo o processo de produção.

O Manual de Boas Práticas de Fabricação de alimentos, uma vez implantado, assegura padrões de qualidade mínimos para os produtos, bem como determinam os procedimentos de elaboração dos alimentos e de higiene corretos a serem utilizados.

Após a confecção do Manual de Boas Práticas de Produção e sua implantação na Distribuidora de Gelo Paranoá, foi possível verificar um ganho na qualidade do produto, que passou a ser assegurado por análises microbiológicas e fisico-químicas periódicas, alem de possibilitar um transporte e armazenamento adequado para o produto 


\section{8 - Bibliografia}

- BRASIL. Ministério da Saúde. Portaria n. 36 de 19 de Janeiro de 1990. Dispõe sobre as normas e o padrão de potabilidade da água destinada ao consumo humano, a serem observados em todo o território nacional. Diário Oficial da República Federativa do Brasil, Brasília, 23 jan. 1990, p.1651. Seção 1.

- BRASIL. M.A.A. Portaria 326 de 30/07/97. Regulamento técnico sobre as condições higiênico-sanitárias e de boas práticas de fabricação. Diário Oficial da União, p. 2833, de 01/08/97.

- BRASIL. Ministério da Saúde. Secretaria de Vigilância Sanitária. Portaria no 326, de 30 de julho de 1997. Regulamento Técnico sobre as Condições Higiênico-Sanitárias e de Boas Práticas de Fabricação para Indústrias de Alimentos. (www.planalto.gov.com.br)

- BRASIL. Ministério da Saúde. Secretaria de Vigilância Sanitária. Portaria nº 1428, de 26/11/93. Regulamento Técnico para Inspeção Sanitária de Alimentos” onde, entre outros pontos de grande importância, são definidos: a Inspeção Sanitária ; o Laudo de Inspeção; a Cadeia Alimentar, e, o sistema de Análise de Perigos e Pontos Críticos de Controle- APPCC (www.planalto.gov.br)

- Brayle, D. trad. Manual de orientação sobre controle dos riscos dos produtos de pesca. FDA Regulamentos (21 CFR 123). FAO, 1990. Fortaleza, 1997. CAC/RCP 1-1969, Rev. 3 (1997). In: Codex Alimentarius Comission. Codex Alimentarius. Volume 1: General Requirements. 2a. Rome: FAO, 1997. 
- Codex Alimentarius Commission. Codex Alimentarius. Volume 1: General Requirements. 2a ed. Rome: Food and Agriculture Organization of the United Nations, 1997.

- CHRISTOVÃO, D. A. et al. Padrões bacteriológicos. In: Água, qualidade, padrões de potabilidade e poluição. São Paulo : Companhia Estadual de Tecnologia de Saneamento Básico e Controle de Poluição das Águas, 1974. p. 57-119.

- DIAS, J. W. Analises de Perigos e Pontos Críticos de Controle. : Brasília : Apostila CET/ Qualidade em alimento 2003

- SILVA Junior , E.A. ; Manual de Controle Higiênico Sanitário em Alimentos; $4^{\mathrm{a}}$ edição; São Paulo; Editora Valera; 2001

- SOUZA,H.B.; DERISIO,J.C. Guia técnico de coleta de amostras de água. São Paulo : CETESB, 1977. p. 195-199.

- ROCHA. Padrões bacteriológicos. In: Água, qualidade, padrões de potabilidade e poluição. São Paulo : Companhia Estadual de Tecnologia de Saneamento Básico e Controle de Poluição das Águas, 1974. p. 57-119. 
9- Anexo 